\title{
Building Innovative Leadership Capacity: A Perspective on How to Stabilize Exploration and Exploitation in the Railway Sector in Ghana
}

\author{
Mighty Daniel Laryea Aryee Zhao Xiu Li John Mahama Akpanyi \\ School of Management, Jiangsu University, 301 Xuefu Road, Jingkou District - Zhenjiang, China
}

\begin{abstract}
The purpose of this article is to suggest whether an ambidextrous organization can be created from the bottom up. This is achieved by incorporating studies on contextual ambidexterity and capacity building for individuals and organizations. The conceptualization of a capacity construction for innovation structure indicates how to maintain the equilibrium among both exploration and exploitation. This research is conceptual backed by interviews in the railway sector of Ghana, focusing on the connections between the two theoretical views, the benefits of the suggested structure for innovation and capacity building for management. The Innovation and Leadership Capacity Building Framework discusses the impact of ambidexterity on the rail sector, both positive and negative, and the interactions required, such as feedback between the management team and employees, so that they can build an ambidextrous working culture in the sector together. A culture where the individual worker is accountable for changing between exploration and exploitation operations and in which the leadership team empowers staff to be there. This research is focused on contextual ambidexterity and when to implement contextual ambidexterity as a manner of working in Ghana's rail industry. The originality resides in the suggested structure and can be enforced in the industry in the devoted focus on "how".
\end{abstract}

Keywords: Exploration-exploitation, Leadership, Organizational learning, Contextual Ambidexterity, Capacity Building, Railway Sector, Ghana

DOI: $10.7176 / \mathrm{EJBM} / 11-30-05$

Publication date:October $31^{\text {st }} 2019$

\subsection{Introduction}

We live in a leadership era. There is widespread recognition of the importance of leadership capacity by governments, corporations, businesses and organizations of all kinds. Belief in the transformative influence of leadership seems to outstrip the research and scholarship that would underpin its justification. Organizations operating in uncertain external conditions need to pursue competing objectives of efficiency and innovation simultaneously. A central concern in the study of leadership processes is to develop capabilities for being efficient as well as responsive to new changes in the environment. These processes cover three activities: Technical growth, development of systems and organization strengthening. These activities are really needed in the railway sector of Ghana to revive it operations in Ghana since it is barely operating. Innovation is the mechanism by which organisations produce new products, processes and systems required for adapting to changes in the markets, technologies and forms of competition (Lawson and Samson 2001). Other androgyny - related training methods have proved more relevant in addition to the training methods purely technical and traditional formed through state authorities and NGOs (Philippe 2004). As a result, capacity building is concerned with the subsequent change. The theories of change evolved many years ago have produced an enormous literature in various disciplines (Brix 2019). Based on this literature, it appears that the idea of modification is polysemous as it stands for both changes to the feature (an operating method) and the conversion of how these various aspects are subject to regulation. As stated by (Choi and Chandler 2015) changes in public action can be considered if the following evidences are observed: the change in policy objectives; the modification in the tools used to make public action effective; and the modification in the institutional framework that guides development which is focused on public achievement. These companies are mostly referred to as "ambidextrous", studies reveal that, both public and private companies can identify and maintain this delicate balance (Uotila, Maula et al. 2009).

The railway sector of Ghana needs a massive revival to enhance it operation hence the study, however, it is not an easy task to build an ambidextrous railway sector. It is debated that, because of the pay-offs relating to the exploration and the exploitation (Organizational learning), unreasonable activities are well established (Brix 2017). When organizations exaggerate exploitation, it reduces the learning of new skills and becomes confined to the outdated skills, technology, etc which decrease performance (Palm and Lilja 2017). Also, when organizations exaggerate exploration, its risk using the scarce resources and receiving unsatisfactory paybacks, thereby depriving short-term aid (Hoang and Rothaermel 2010). According to (Gaim and Wåhlin 2016) it is tough to move from exploration to exploitation even though the railway sector have the most expertise to steer their present state, which is most frequently considered as either exploitative or explorative. One explanation for this is likely because, exploitation provides to less problems as well as less opposition from members of the organization, whiles 
exploitation on the other hand, helps organizations achieve efficiencies, better utilize resources and remain competitive. Organizations need exploration to seek new resources and develop new competencies to promote innovation and meet future challenges (Palm and Lilja 2017). The dilemma of ambidexterity, hence the problem of exploration-exploitation, is linked to two diverse perspectives. It's argued that, exploratory and exploitative knowledge is incompatible as they are contending for the same assets and this claim reflects the opinion of divergence (Smith and Tushman 2010). There are other claims that says, the two strategies to learning have complementary advantages and this argument denotes the understanding of integration (Gibson and Birkinshaw 2004). Therefore, the question is, how to deal with the problem of ambidexterity in the railway sector. The literature put forward that, the way out is structural ambidexterity. Structural ambidexterity brings up the decision to divide the work into diverse sectors with exploration and exploitation (Andriopoulos and Lewis 2009). The sequential ambidexterity is also a different approach to the dilemma (Raisch, Birkinshaw et al. 2009). It brings about the process of changing from one end to the other, that is by carrying out the change in managerial curricula (O'Reilly III and Tushman 2013).

According to (Wei, Yi et al. 2014) these kind of literature streams depict the stance of diversity. Although existing studies has offered many understandings into the benefits and obstacles of exploration and exploitation, an organization's understanding of how ambidexterity can be diversified is still low (Choi and Chandler 2015). Stating from (Raisch, Birkinshaw et al. 2009) below is essential problematic: Research on ambidexterity generally describes the processes of organization that allow ambidexterity, for example hierarchical systems or mechanisms of lateral coordination. In contrast, various research shows that ambidexterity is entrenched in the capacity of an individual to explore and exploit. Institutional structures might be necessary to enable ambidexterity at the basis of the individual, and ambidextrous individuals may be very important to the organizational structure's purpose. The theories capturing ambidexterity across multiple analytical scales are therefore important. Also, (De Clercq, Thongpapanl et al. 2013) made it known that, the development of ambidexterity has been directly associated with organizational ambidexterity and sequential ambidexterity more recently, however, authors have started to emphasize the significance of bottom-up strategies to deal with the problem of ambidexterity, that is to say, contextual ambidexterity. The contextual ambidexterity is part of the opinion on integration and brings up the behavioural ability to show adaptability and alignment simultaneously covering the total unit of the business (Wang and Rafiq 2014). That is to say, the problem of ambidexterity can be determined by understanding management and employee behaviours and their interactions in their contextual work environment related to exploration and exploitation, as contextual ambidexterity is a theoretical construction that is relatively new (Wang and Rafiq 2014). In relation to (Havermans, Den Hartog et al. 2015) appeal to learn how contextual ambidexterity could be accomplished by including managers and workers, and situations where this role can be successful in the railway sector of Ghana.

This research's main objective is to respond to the call by exploring how the literature works on the organizational and individual capacity building will be used as a theoretical framework in established organizations like the railway sector of Ghana to build and maintain contextual ambidexterity (Brix 2019). In this relation, capacity building is explained as task that enhances individuals' knowledge, expertise, behaviour and improve institutional structure and processes so that the organization can effectively meet its objectives in a sustainable manner (Ku and Yuen-Tsang 2013). A fundamental goal of capacity building is to enhance the ability to evaluate and address the crucial questions related to policy choices and modes of implementation among development options, based on an understanding of environment potentials and limits and of needs perceived by the individuals of an organization concerned. A structure for an innovation capacity-building is created on the basis of this theoretical integration. The greatest part of the research is the structure, which suggests how organizational and individual capacity building procedures will be implemented by managers to empower employees to make appropriate judgements between exploration and exploitation in order to achieve both their own objectives and work in the direction achieving the expected strategy of the organization (Havermans, Den Hartog et al. 2015). This strategy from the bottom up and high emphasis on the interaction between manager and employee in the railway sector of Ghana, resonates with the research of efficient execution procedures, which indicate that, contextual ambidexterity might materialize due to their diverse environmental perceptions and efforts to respond to perceived changes in the environment, the relationship between leaders and their team members. By adding a perspective for capacity building into the ambidexterity literature and thus through the research of organizational learning, this paper provides a dual understanding of how to develop the top management team into the organization's capacity to promote the ambidexterity context (the railway sector capacity building) whilst inspiring individual workers simultaneously and building their capacity to process both exploratory and exploitative learning what to do (individual capacity building in the railway sector) (Brix 2019). The concern thus addressed in the study is not "why" to maintain a balance between exploration and exploitation in the railway sector of Ghana, but rather to address the issues of "how" an organization like the railway sector of Ghana can build its capacity for survival and prosperity on the basis of the resources available to it (Gaim and Wåhlin 2016). Therefore, there's a step back to evaluate the processes that brings about an institution and its workers being able to continue to be important in 
their environment by building their capacity to act in an ambidextrous manner.

This work will take the theoretical background into account and will discuss the literature on contextual ambidexterity and organizational / individual capacity building in Ghana's railway sector. In addition to providing a synthesis of the key issue proposed in Ghana on innovation management and capacity building, brief review on leadership and finally ending with the conclusion of the study.

\subsection{Literature Review}

\subsection{Theoretical Background}

Two sub-sections divide the theoretical background. First, the contextual ambidexterity literature is analysed to shape the scope where the process of capacity building is to take place. The literature on individual and organizational capacity building is subsequently examined to explain and refine the method and ideas of how capacity building takes place so that it can be included in the contextual ambidexterity organizational sector (Ghana's railway sector).

\subsection{Contextual ambidexterity}

Contextual ambidexterity is defined as "the behavioural capacity to show continuous positioning and flexibility across a whole business unit". Consequently, contextual ambidexterity focuses mainly on behavioural and social means of integrating exploration and exploitation as a balancing act against structural and sequential ambidexterity (Andriopoulos and Lewis 2009). Structural ambidexterity pertains to the division of job related to exploration and exploitation in various institutional units, which may also contribute to integration issues in the parent organization (O'Connor, Corbett et al. 2018). Sequential ambidexterity pertains to the application of (larger) institutional change-management assignments over a period time (O'Reilly III and Tushman 2013). Deducing from (Gibson and Birkinshaw 2004) work on contextual ambidexterity, it was stated that, supporting social processes (e.g. practices of socialization and recognition), culture and interpersonal relations enable performers to think and act ambidextrously throughout the firm (Andriopoulos and Lewis 2009), also (Brix 2017) stated that, contextual ambidexterity like many other theories of organizational learning, is a multi-level phenomenon.

Contextual ambidexterity involves at least two units of analysis of the organization in which the dilemma of ambidexterity is manifested and its influence on the judgments of the individual employees on how best to divide their work between conflicting exploration and exploitation requirements (Havermans, Den Hartog et al. 2015). The organizational context must be cantered on: stretch, discipline and trust interaction if the individual "change" between tasks of the employees is to be promoted and performed (Gibson and Birkinshaw 2004). On the level of the individual, the transitioning between exploration and exploitation activities can consist of sequential ambidexterity where short exploration phases (minutes or hours) get to be part of everyday operations routine work (Raisch, Birkinshaw et al. 2009).

\subsubsection{Advantages related to contextual ambidexterity.}

According to (O'Reilly III and Tushman 2013) in their work concluded that, ambidexterity is strongly associated with performance improvement of the business unit, regardless of whether it is structural, sequential or contextual. The contextual ambidexterity allows diverse business operations to be processed in parallel (Gibson and Birkinshaw 2004). In particular, this concerns organizations doing business in dynamic environments which often have no option but to unify existing companies while identifying and developing new opportunities at the same time. In the study conducted by (Simsek, Heavey et al. 2009) made it known that, the contextual ambidexterity signifies a greater organizational learning approach as matched to the other two kinds of ambidexterity.

On the other hand, (Wang and Rafiq 2014) supported this statement in their research indicating that, contextual ambidexterity represents the growth of a whole company focused on the unification of exploration and exploitation through an organizational learning process, thus ignoring the cost of coordination caused by structural separation and the cost of transition due to temporary separation. Another statement made by (O'Reilly III and Tushman 2013) in their study support the claim that, contextual ambidexterity allows for a high degree of effectiveness in current work flows, since individual workers can chose to break the current routine and examine whether new differences in the work process will make their work more productive. They also stated in the study an advantage of contextual ambidexterity that it leads to greater transparency to modify and improve responsiveness to new business unit opportunities. The argument in this regard is based on the practical experiences of the employees and the building of skills in both exploration and exploitation.

It allows workers to make a significant contribution and execute in both fields (Brix and Peters 2015). It increased performance in both exploration and exploitation is believed to result in a better track record and prestige for the firm (Güttel and Konlechner 2009). It was also stated (Simsek, Heavey et al. 2009) that, the productive application of contextual ambidexterity can be seen as a source of competitive edge, as this parallel processing of contradictory needs of the Ghana Railway sector is useful, uncommon and expensive resource to emulate.

2.2.2 Disadvantages related to contextual ambidexterity.

Below are some of the detriments affecting contextual ambidexterity that will be discussed in this study. According 
to (De Clercq, Thongpapanl et al. 2013) the significant resources and managerial initiatives must be invested in order to improve superior capacity to reinforce the two contrasting forces. The authors argued that successful application involves resource conflict mitigation, suitable leadership styles, helpful incentive structures and knowledge of the conceptual systems that allow the appropriate decision of the individual workers who are liable to change (Havermans, Den Hartog et al. 2015). (O'Reilly III and Tushman 2013) stated that, the task of the management staff and also the leaders in aid of contextual ambidexterity is more indecipherable.

A weak operational strategy application decreases the estimated outcomes of ambidexterity placement because managerial level assumes that the ability of workers to change among duties already exists (O'Cass, Heirati et al. 2014). The core concern is to prevent damaging relationships among people who may encounter contradictory preferences when, as part of their integration, exploration or exploitation tasks, are given different preferences. This will seriously affect the Ghana Railway Sector, if the goals of the sector and the expected outcome related to their goals are not mitigated well (De Clercq, Thongpapanl et al. 2013).

\subsubsection{Implementing contextual ambidexterity: enabling mechanisms.}

As explained in the above section, a complex social phenomenon is the adoption of contextual ambidexterity (Krogstrup 2016). It is argued that the appropriate orchestration of the employees and their knowledge and supporting processes is imperative to build an organizational culture and context that enables the requirements for ambidextrous work of the employees (Gaim and Wåhlin 2016). The adoption of contextual ambidexterity involves a change in the approach of management, i.e. from a traditional top-down approach that highlights the function of leadership, the official framework and governance to a bottom-up learning approach that recognizes the function of members in their growth and organizational culture and interdisciplinary exploration and exploitation abilities are shaped (Wang and Rafiq 2014). If the application method is properly planned and executed, (O'Cass, Heirati et al. 2014) declare that: capacity will be integrated into organizational routines and processes over time. The literature therefore considers organizations to always be able to accept the positive results / implications of the ambidextrous prospects if the application is successful. Moreover, limited knowledge on "how" contextual ambidexterity is still available in practical terms. By showing the theoretical background on organizational and individual capacity building, the basis for a novel standpoint to this black box of ambidexterity is provided below.

\subsection{Individual and organizational capacity building}

When we talk about capacity building, it has no commonly recognised definition. This is because it has a lot of definitions that best suit it and also many ways to analyse (Jensen and Krogstrup 2017). Given that this manuscript is aimed at building innovative management and leadership capacity, the literature stream used in this conceptualize below is based on the work of current literature by renowned scholars. This stream of literature frames capacity building as a method of enhancement which concentrates on an organization's leadership and employees ' efforts and connections to sought their full capabilities. Figure 1 shows the similarities in capacity building between individual and organizational levels of analysis (Krogstrup and Brix 2019). One of the challenges in defining capacity building is centred on the impermanence of the construction, according to (Jensen and Krogstrup 2017), capacity building is a method and a result. It is a method because it focuses on developing people ' existing abilities. It is also a result because even as a result of this capacity building method, the capabilities are enhanced. Capacity building is a consistent improvement of potential, it also refers to the need for more growth as well as the need for new skills that can empower the formulation and accomplishment of their own objectives (Jensen and Krogstrup 2017). (Ku and Yuen-Tsang 2013) provided another definition that clearly embraces the individual and organizational levels of evaluation. Capacity building is known as the practices that enhance individuals' understanding, expertise and enhance institutional structures and procedures to enable the organisation to achieve its objectives effectively in a viable manner (Ku and Yuen-Tsang 2013).

Besides this, the method of building capacity is also context-dependent. The argument is that it is the current capabilities of the organisation and its staff that define the policies and operations to be implemented in order to initiate and sustain appropriate local enhancement projects (Labin, Duffy et al. 2012). The exterior frame of person and organisational procedures for capacity building illustrated in Figure 1 shows the dependency of the context. (Jensen and Krogstrup 2017) further emphasize the basis for context dependence improvements are unlikely to be successful if the human needs for this capacity building are often not available in the organisation and if not, all stakeholders create contractual ownership of the modification. Capacity building therefore has a provisional direction towards an enhanced future state being achieved. It means that, if any of the arrows between employee as well as the extent of assessment organization is also not available in Figure 1, the process of capacity building cannot generate the development required in the particular context. It is therefore essential to emphasize that this method of dual-level person and organizational development concerns both the organisational context for capacity building and improving the ability of individual staff to achieve current objectives and to identify and frame new objectives (Farazmand 2004); (Labin, Duffy et al. 2012). 


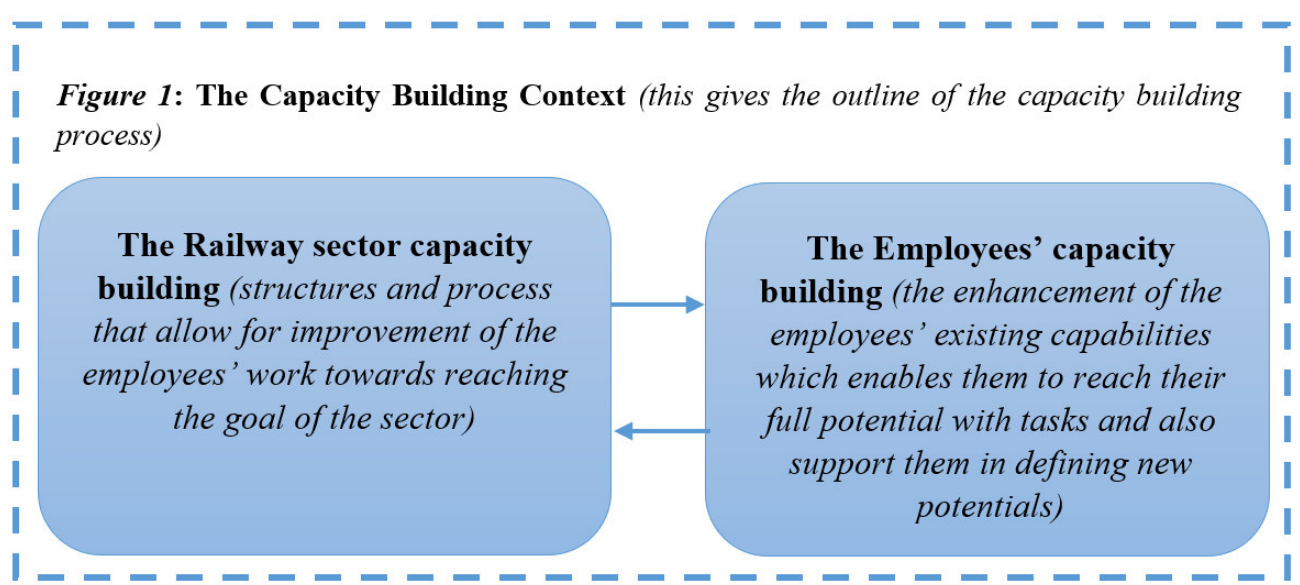

Source: Author's context

Table 1 is implemented to describe and clarify the many main constructs used for this research to unfold the tradition of capacity building studies.

\begin{tabular}{|c|c|c|}
\hline $\begin{array}{l}\text { Theoretical } \\
\text { framework }\end{array}$ & $\begin{array}{c}\text { Sub- } \\
\text { framework }\end{array}$ & Definitions \\
\hline \multirow[t]{5}{*}{ Capacity Building } & Organization & $\begin{array}{l}\text { Supporting and enhancing structures, procedures and opportunities } \\
\text { that aid staff and executives in achieving the organization's strategic } \\
\text { objectives }\end{array}$ \\
\hline & Individual & $\begin{array}{l}\text { The regular improvement of the current capacities of the employee } \\
\text { and his / her capacity to identify the new capacities required to } \\
\text { achieve new objectives; and the capacity to set new objectives for } \\
\text { them }\end{array}$ \\
\hline & Direct & $\begin{array}{l}\text { Learning through structured professionalization, studying, read } \\
\text { books and publications related to work, and getting advice from } \\
\text { outside experts }\end{array}$ \\
\hline & Indirect & Learn, focus, modify (if needed) and attempt once more \\
\hline & Innovation & $\begin{array}{l}\text { Is a method in which an organisational context is developed that } \\
\text { promotes the use and growth of the understanding, abilities and } \\
\text { decision-making abilities of staff through managerial feedback so } \\
\text { that staff are empowered to know when to move between } \\
\text { exploration and exploitation operations }\end{array}$ \\
\hline \multirow[t]{3}{*}{ Empowerment } & Relational & $\begin{array}{l}\text { Briefly describe how decision-making authority is shared between } \\
\text { the leadership team and the staff }\end{array}$ \\
\hline & Motivational & $\begin{array}{l}\text { Workers are conscious of their own abilities and expertise in } \\
\text { addressing their duties so that they are inspired to take on fresh } \\
\text { duties }\end{array}$ \\
\hline & Technological & The (new) technology cannot be used or accessed \\
\hline \multirow[t]{3}{*}{ Disempowerment } & Political & $\begin{array}{l}\text { Uncertainty as to who is responsible for the choice in a specified } \\
\text { scenario }\end{array}$ \\
\hline & Social & Unclear, what is anticipated in a particular scenario \\
\hline & Psychological & Lack of confidence, time or ability to tackle a particular job \\
\hline
\end{tabular}

Source: Author's context

\subsubsection{Direct or indirect capacity building.}

Capacity building in the literature is split into two methods: direct capacity building and indirect capacity building (Krogstrup 2016). Significant capacity building involves the official professionalization of skills that can be achieved, like attending classes, pursuing specific master programs, reading books and publications, or seeking guidance from the external consultants. Direct capacity building is thus a circumstance where student-teacher interpersonal connection is active or passive (Lane and Lubatkin 1998). The simplest explanation for indirect capacity building is learning by just doing (Krogstrup 2016). A particular initiative is described, implemented and evaluated in indirect capacity building to reflect the production and results of the initiative. Learning out of this observation can be used to reinterpret the approach over the next process to produce better results (Labin, Duffy et al. 2012). Thus, a top management staff can also provide exposure to immediate capacity building by providing 
comprehensive skills and frameworks in the staff (and their own) for the (fresh) work to be accomplished (Farazmand 2004). When all the authorization is granted to the staff to permit them to perform the (new) task, indirect capacity building may well arise and therefore will evaluate losses in the culture, structure and procedures of the organization that counteract the strong mandate of the staff (Farazmand 2004).

Determining such unhelpful product will allow the management team and staff to alleviate them, so that fresh efforts can also be introduced to address the mission and improve efficiency. The claim has been that, capacity building in this respect allows an organisation and its employees to: address and handle continuing difficulties and behave far beyond them by operating via expectation, efficient visions, proactive understanding and abilities, and self-correcting organizational behaviour (Farazmand 2004). Directly connected to this, it is again stressed that employees ' capacity and encouragement to act on prospective possibilities for enhancement or innovation is essential and that the managerial authorization for doing so is present (Honadle 1981). As said by (Noya and Clarence 2009) and (Jensen and Krogstrup 2017), this double aim is accomplished via the importance placed on sustainability of the capacity building literature. Figure 2 is provided at this stage to supplement the theoretical definitions described in Table 1. Figure 2 shows a hierarchy of these theoretical constructs that have been debatedand will be addressed.

Figure 2: Capacity Building Framework

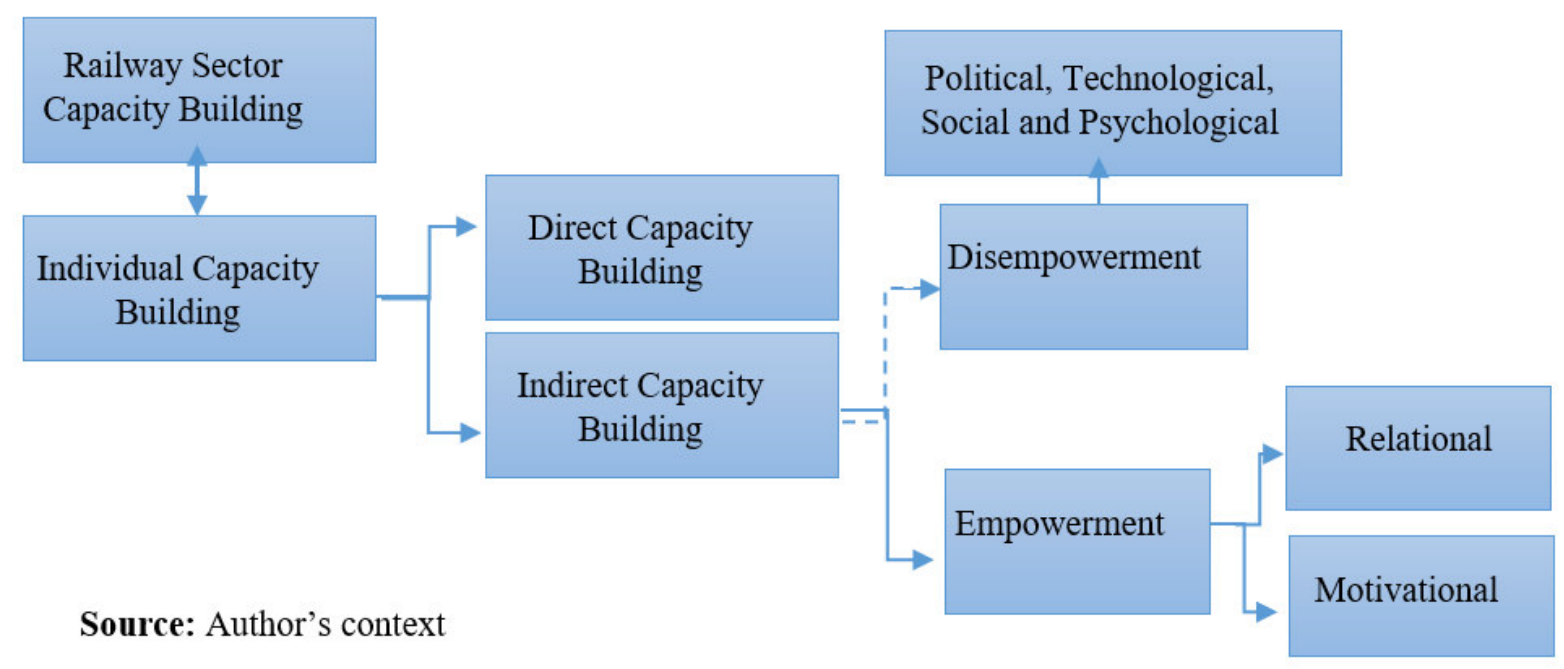

\subsubsection{Empowerment-orientation in capacity building.}

According to (Krogstrup and Brix 2019), involvement in capacity building is split into two views: a) Motivational View; and b) Relational View. In the motivational view, the concentration is on attaining a greater degree of personal-awareness for the person by defining and enhancing their abilities and skills to generate private empowerment. In this view, the person is also provided the responsibility to make choices to the standard that he/she has the ability to assume this mandate (Conger and Kanungo 1988); (Spreitzer 1995); (Fetterman, Liu et al. 2015). The conceptual view focuses on the dependence of the partnering actors on one another (Spreitzer 1995). In this respect, the emphasis is on how authority is allocated to decision-making among the partnering actors. Thus, the capacity building empowerment view sets out two significant subcategories:

\subsubsection{Disempowerment-orientation in capacity building.}

The concept of disempowerment is a significant element of empowerment-orientation (Lennie 2005); (Krogstrup and Brix 2019). Disempowerment is a sense of being incapable of delivering or accomplishing something that others hope to do. There are several factors that contribute to disempowerment, as per (Lennie 2005), like uncertainty about fresh projects (social disempowerment), failure to use or adapt (new) innovation (technological disempowerment), confusion as to who is actually responsible for decision-making in project partnerships (political disempowerment), or absence of trust, power or ability to tackle the job at hand (psychological disempowerment) (Lennie 2005). As per (Krogstrup and Brix 2019), before beginning fresh projects, it is essential for executives to be conscious of prospective disempowering processes in organisations. If these structures are recognized, these structures must be corrected or mitigated by managerial behaviour. In certain terms, if there are disempowering procedures - which could be demonstrated as broken arrows depicted in the Figure 1 - then the production and outcome of the procedures of constructing person and organisational ability will not be achieved (Krogstrup 2016); (Krogstrup and Brix 2019). This contribution to literature on contextual ambidexterity as well as the literature on building employee and organisational ability explains the theoretical context of the research. 


\subsection{Discussion and Implications}

The main reason for incorporating capacity-building literature with contextual ambidexterity literature has been one of untapped interdependence: little is understood about the real procedures of generating an ambidextrous organizational culture in contextual ambidexterity literature (Wang and Rafiq 2014); (Havermans, Den Hartog et al. 2015), the ambidexterity context has not been explored in person and organisational capacity building (Farazmand 2004); (Krogstrup and Brix 2019). This complementarity is argued as both theoretical positions take a behavioural perspective on individual and organizational development and both emphasize the importance of the influence of the context on the actual subject and method to be adopted (Wang and Rafiq 2014); (Jensen and Krogstrup 2017). The preceding are claims which provide the demands for fresh theoretical ideas centred on multilevel conceptualization of the framework for the development of innovation capability.

\subsection{What is innovation capacity building?}

Innovation Capacity Building is a method where an organisational context is developed which promotes the use and growth of the information, talents and decision-making expertise of staff through managerial comments in such a manner that staff are encouraged to identify when to move between exploration and exploitation operations. According to (Krogstrup 2016), capacity building for innovation is therefore described as a proactive approach. The aim of the whole approach is on communication between executives and staff on how organisational context, culture and management impact employee's behaviour and behaviours when shifting between exploration and exploitation, and vice versa (Labin, Duffy et al. 2012); (O'Cass, Heirati et al. 2014). The simple definition fulfils the requirements for the effective application in practice of contextual ambidexterity stated by (Havermans, Den Hartog et al. 2015), as a multi-level knowledge of adaptive procedures between staff and the managers is in practice (Andriopoulos and Lewis 2009). The "How" parts of Table 2 illustrates these engaging procedures.

Table 2: The Engaging Procedures

\begin{tabular}{|c|c|c|c|}
\hline & The Railway Sector & Individual & Empowerment \\
\hline What & $\begin{array}{l}\text { Context promoting the employee's } \\
\text { use and growth of information, } \\
\text { abilities and decision-making } \\
\text { capacity in relation to the planned } \\
\text { approach }\end{array}$ & $\begin{array}{c}\text { Continues to improve the } \\
\text { understanding, abilities and } \\
\text { decision-making qualities of the } \\
\text { employee in regards to their } \\
\text { duties }\end{array}$ & $\begin{array}{l}\text { Employees feel that they're } \\
\text { in command and can } \\
\text { prioritize the right changes }\end{array}$ \\
\hline How & $\begin{array}{l}\text { Constantly responding to the } \\
\text { organisational framework by } \\
\text { evaluating feedback from the } \\
\text { activities, attitudes and outcomes } \\
\text { of the respective employees }\end{array}$ & $\begin{array}{l}\text { Periodic feedback and assistance } \\
\text { for the activities and attitudes of } \\
\text { respective employees when } \\
\text { shifting between exploration and } \\
\text { exploitation }\end{array}$ & $\begin{array}{l}\text { As the required behaviour } \\
\text { and actions are created, the } \\
\text { individual worker is } \\
\text { increasingly empowered }\end{array}$ \\
\hline
\end{tabular}

Source: Inspired by (Krogstrup and Brix 2019)

Table 2 is conceptualized to illustrate the "what" and "how" of the connection between the capacity building system at the organisational level and the connectivity of the organisational level with the individual capacity building system and individual engagement. Furthermore, the simple definition makes it very clear the mechanism that describes: what competent organisations do (Honadle 1981) and emphasizes that capacity building for innovation is a: social product that is not created by individuals, but in communication between individuals (Krogstrup 2016). The objective of building innovation ability is to improve the organisation and its staff continually such that the planned objective can be achieved. To this end, the priority is on using current expertise and skills as effectively as possible, while at the same time improving these understanding and skills in order to create fresh, smarter methods of working (Farazmand 2004); (Jensen and Krogstrup 2017). As a wakeup call, the "what" and "how" segments in Table 2 clarify this view. Innovation capacity building is therefore asserted to be a method that allows current organisations to create contextual ambidexterity. This statement is evaluated by explaining how to achieve innovation capacity building in a specified context by addressing the new responsibilities assigned to executives and staff (Gibson and Birkinshaw 2004); (Wang and Rafiq 2014).

\subsection{How is innovation capacity building achieved?}

Figure 3 below illustrates the shift from a non-ambidextrous organisation to an ambidextrous institution (the procedure of capacity building) in a streamlined way. Figure 1 highlighted the context-dependent capacity building mechanism at an institutional and individual level, and hence the emphasis throughout the preceding debate is on capacity building mechanism, not content. The function of leadership is to allow staff to access appropriate projects linked to their work and linked to the direct capacity building. It was recalled that, direct capacity building concerns books and publications connected to job, e.g. formal professionalization measures, course work and reading. 
Figure 3: The shift from a non-ambidextrous organisation to an ambidextrous institution

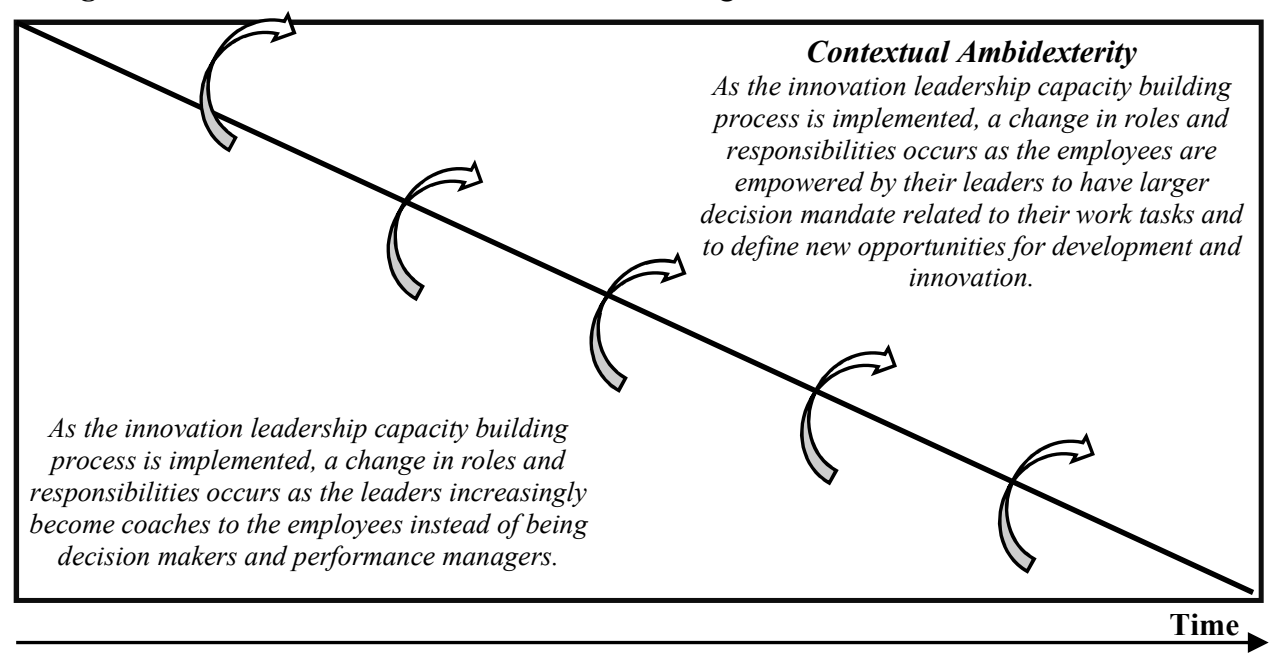

Source: (Brix 2019)

The next significant function of leadership is to assist staff and to provide feedback on the learning through doing" when switching among exploration and exploitation job duties to staff. The learning cycle bullets in Figure 3 demonstrates these updates. In other sayings, it is the task of the management to concentrate on the significance of employees' indirect capacity building. As leadership guidance and the own thoughts of the staff on their learning by doing are used to enhance the job procedures, individual staff can also improve their feeling of motivational empowerment. As previously mentioned, motivational empowerment relates to circumstances where a person feels in command of his / her position and is capable of fulfilling his / her work. In regards, the leadership would need more decision-making authority (interpersonal empowerment) from the worker if he/she feels willing to assume this mandate. These are the managers' significant (fresh) duties linked to contextual ambidexterity in their new positions. The function of staff shifts as they are generally empowered to take accountability for operating ambidextrous rather than in organisations where top-down structural or sequential ambidexterity is officially accepted (Gibson and Birkinshaw 2004).

Since contextual ambidexterity needs a bottom-up view, it is essential that management doesn't really expect all staff to feel able to assume this obligation. A choice to alter the approach overnight could lead to confusion and therefore the sensation of' social disempowerment' and thus counteract the initiative being introduced (Farazmand 2004); (Brix 2017). If this were to happen, the management's good initiatives would bounce back and the employee would need a more top-down decision-making style, taking the value and benefits of contextual ambidexterity outlined in Section 2.2.1 of the implementation strategy. Indirect capacity building can be used as a tool for evaluating and providing feedback on the present state of employee motivation and skills to switch between exploration and exploitation when implementing the bottom-up approach.

The feedback loops in Figure 3 that illustrate this scenario is again referenced. As staff show positive behaviour, self-reflective and self-correcting attitudes in their work, leadership can empower the person with a bigger decision-making mandate (relational empowerment). This might take longer, as contextual ambidexterity in a non-ambidextrous organisation is argued to be an extremely difficult way of working (Gibson and Birkinshaw 2004); (Simsek 2009); (Gaim and Wåhlin 2016). Reference is produced to Figure 3 for execution, which explains the shift from "company as usual" to an organisation aimed at building capacity for innovation. It is essential that feedback is provided continually throughout the organisation between executives and staff so that acting ambidextrously becomes an important component of job descriptions, work assignments and organizational culture, and so acting ambidextrously does not include only the few chosen champions innovation (O'Connor, Corbett et al. 2018). But here are tangible examples of how feedback-related content can be activated between executives and staff.

\subsubsection{Enabling feedback and self-corrective behaviour.}

As per (Honadle 1981), if the capacity building method is to be enhanced, there requires to be a regular evaluation of what is being accomplished. Encouraged by (Honadle 1981), the examples below demonstrates practical questions that can be used in an organisation seeking to move from the left to the correct side of Figure 3 to allow this evaluation job: Is the ability of staff to change from exploration to exploitation sufficient, are there obstacles that prevent staff from switching, is the sheer quantity of exploration and exploitation activity suitable and could we somehow do better? (Honadle 1981) is setting up a three-step strategy to operationalize the evaluation job in relation to these issues.

First, one should monitor what is presently being done by the organisation and its members. 
Secondly, an assessment of how well they seem to do it must be performed,

And last but not the least, an assessment of whether the present amount of effort is adequate over time.

These three steps and their issues could be introduced and act as mechanisms for creating understanding about the gaps between current organisational and individual capacity for contextual ambidexterity within a specified organisation. More significantly, the understanding generated through these measures could provide the basis for defining the necessary adjustments to these organisational and individual capabilities to construct the basis for an ambidextrous institution in context (Farazmand 2004); (Simsek 2009); (Palm and Lilja 2017) as an essential aspect of the process of building capacity for innovation.

\subsection{Leadership}

The aim of classical management schemes was to create a set of values or expertise and abilities that previously acknowledged leaders or had powerful and charismatic people (Kennedy, Carroll et al. 2013). Well into the literature, techniques such as skill set approaches (Kennedy, Carroll et al. 2013) or skill set attitude to management (Bolden and Gosling 2006) have now been acknowledged. Governance suitability approach has been questioned as restricted in scope and flexible where skills and expertise have been "continually used in the long run to provide a feeling of limits (or structure that is restrictive) to "management" and now "leadership" processes" (Bolden and Gosling 2006). Requests from establishments, organizations, networks of social activists and researchers have reworked the leadership debate to include a more worldwide and collective perspective by expanding these individualistic boundary structures. Unfortunately, this development could not be achieved without using the teaching literature of skills and competencies (Dugan, Bohle et al. 2014) Studies emphasized the necessity to evolve "leadership capabilities before proceeding to more complicated group-related process capabilities" (Day, Harrison et al. 2009). Presenting indigenous studies on management and leadership growth in the more global setting had have become far more vital (Zhang, Fu et al. 2012).

Leadership findings in individuals complicated conduct, reacting in a non-linear fashion, interactively. Traditional management skills have to be lively, respectful (McCarthy 2014), open (Gagnon, Vough et al. 2012), a team player (Brown, McCracken et al. 2011) or inspiring (Fambrough and Kaye Hart 2008) as well as being able to advance the team/group forward (Antes and Schuelke 2011). Other leadership research concentrated on management as "which is more about the sense of identity of the leader than she or his qualities or skills" (Warhurst 2012), Concerning leaders "settled in a sense of identity" (Muir 2014) and cooperative with shared management positions (McCauley-Smith, Williams et al. 2013). With more present opinions of collective leadership, complexity theory (Clarke 2013) and complexity management theory (Uhl-Bien and Marion 2009), previous individualistic opinions of management are questioned. In today's complicated setting, individualistic management opinions are seen to be of restricted importance (Clarke 2013) and less suitable (McCauley-Smith, Williams et al. 2013). Complexity discusses greater ambiguity and uncertainty (Clarke 2013), is non-linear and "reflects more appropriately the complicated nature of management as it takes place in practice" (Uhl-Bien and Marion 2009). More currently, (Turner and Baker 2018) mapped the management concepts addressed in the HRD literature and contrasted these management ideas with the developments encountered by management theory. The management theory developments have developed into four main stages: traditional, newer, collective and international (Turner and Baker 2018); see (Avolio, Reichard et al. 2009) as well. HRD's field has concentrated mainly on traditional and new stages of management with little to no studies in the collective or international management stages (Turner and Baker 2018). Their study outlined the possibilities for HRD to grow and concentrate more on collective and global leadership.

\subsection{Conclusion}

This research allowed us to identify the emergent process of attaining and maintaining a contextual versatile institution with the reinterpretation of the framework for capacity building innovation. This conceptualization brings fresh theoretical perspectives to the contextual ambidexterity studies, that is hardly acknowledged in literature on institutional learning (De Clercq, Thongpapanl et al. 2013); (Wang and Rafiq 2014); (Havermans, Den Hartog et al. 2015). More exactly, capacity-building framework for innovation adds to current studies on organisational learning by explicitly connecting the person and organizational analytical units ranging from capacity building studies to contextual ambidexterity with an upstream strategy (Wang and Rafiq 2014). The capacity building innovation framework shows how to make the following possible: Firstly, it shows how to create a favourable local context that offers staff with skills and instruments to move among explorative and exploitative operations through direct capacity-building. Secondly, it recommends how to make learning-oriented feedback and feedforward relationships between both the leadership team and staff in order to empower staff to use these (fresh) skills and instruments in practice. The conclusion is that this method will allow staff in the railway sector in Ghana to know how to take decisive action and thus enhance their efficiency in combining exploration and exploitation (increasing indirect ability). Researchers and professionals are encouraged to advance or test the intellectualized public service organization structure as well as in private firms where search to become a versatile 
organization is on the biggest approach.

\section{Acknowledgement}

This work was supported by the National Natural Science Foundation of China under Grant [71403108]; the

National Natural Science Foundation of China under Grant [71874012]; MOE Project of Humanities and Social Sciences in China [19YJAZH059]; Jiangsu Provincial Social Science Fund [16JD013]; and the Cultivation Object of Excellent Young Teachers of Colleges and Universities of Jiangsu Province, China

\section{References}

Andriopoulos, C. and M. W. Lewis (2009). "Exploitation-exploration tensions and organizational ambidexterity: Managing paradoxes of innovation." Organization science 20(4): 696-717.

Antes, A. L. and M. J. Schuelke (2011). "Leveraging technology to develop creative leadership capacity." Advances in Developing Human Resources 13(3): 318-365.

Avolio, B. J., et al. (2009). "A meta-analytic review of leadership impact research: Experimental and quasiexperimental studies." The Leadership Quarterly 20(5): 764-784.

Bolden, R. and J. Gosling (2006). "Leadership competencies: time to change the tune?" Leadership 2(2): 147-163.

Brix, J. (2017). "Exploring knowledge creation processes as a source of organizational learning: A longitudinal case study of a public innovation project." Scandinavian Journal of Management 33(2): 113-127.

Brix, J. (2019). "Innovation capacity building: an approach to maintaining balance between exploration and exploitation in organizational learning." The Learning Organization 26(1): 12-26.

Brix, J. and L. S. Peters (2015). "Exploring an innovation project as a source of change in organization design." Journal of Organization Design 4(1): 29-43.

Brown, T., et al. (2011). "'Don't forget to write': how reflective learning journals can help to facilitate, assess and evaluate training transfer." Human Resource Development International 14(4): 465-481.

Choi, T. and S. M. Chandler (2015). "Exploration, exploitation, and public sector innovation: an organizational learning perspective for the public sector." Human Service Organizations: Management, Leadership \& Governance 39(2): 139-151.

Clarke, N. (2013). "Model of complexity leadership development." Human Resource Development International 16(2): 135-150.

Conger, J. A. and R. N. Kanungo (1988). "Behavioral dimensions of charismatic leadership."

Day, D., et al. (2009). "An Integrative Approach to Leader Development: Connecting Adult Development, Identity, and Expertise."

De Clercq, D., et al. (2013). "Shedding new light on the relationship between contextual ambidexterity and firm performance: An investigation of internal contingencies." Technovation 33(4-5): 119-132.

Dugan, J. P., et al. (2014). "The role of social perspective-taking in developing students' leadership capacities." Journal of Student Affairs Research and Practice 51(1): 1-15.

Fambrough, M. J. and R. Kaye Hart (2008). "Emotions in leadership development: A critique of emotional intelligence." Advances in Developing Human Resources 10(5): 740-758.

Farazmand, A. (2004). "Innovation in strategic human resource management: building capacity in the age of globalization." Public Organization Review 4(1): 3-24.

Fetterman, A. K., et al. (2015). "Extending color psychology to the personality realm: Interpersonal hostility varies by red preferences and perceptual biases." Journal of personality 83(1): 106-116.

Gagnon, S., et al. (2012). "Learning to lead, unscripted: Developing affiliative leadership through improvisational theatre." Human Resource Development Review 11(3): 299-325.

Gaim, M. and N. Wåhlin (2016). "In search of a creative space: A conceptual framework of synthesizing paradoxical tensions." Scandinavian Journal of Management 32(1): 33-44.

Gibson, C. B. and J. Birkinshaw (2004). "The antecedents, consequences, and mediating role of organizational ambidexterity." Academy of management Journal 47(2): 209-226.

Güttel, W. H. and S. W. Konlechner (2009). "Continuously hanging by a thread: Managing contextually ambidextrous organizations." Schmalenbach Business Review 61(2): 150-172.

Havermans, L. A., et al. (2015). "Exploring the Role of Leadership in Enabling Contextual Ambidexterity." Human Resource Management 54(1): 179-200.

Hoang, H. and F. T. Rothaermel (2010). "Leveraging internal and external experience: exploration, exploitation, and R\&D project performance." Strategic Management Journal 31(7): 734-758.

Honadle, B. W. (1981). "A capacity-building framework: A search for concept and purpose." Public administration review 41(5): 575-580.

Jensen, J. B. and H. K. Krogstrup (2017). "Capacity Building in the public sector." Research Group for Capacity Building and Evaluation, Aalborg University, Denmark.[Google Scholar].

Kennedy, F., et al. (2013). "Mindset not skill set: Evaluating in new paradigms of leadership development." 
Advances in Developing Human Resources 15(1): 10-26.

Krogstrup, H. (2016). Evalueringsmodeller, Udgave, Hans Reitzel, København.

Krogstrup, H. K. and J. Brix (2019). Co-produktion i den offentlige sektor: Brugerinvolvering i kvalitetsudvikling, Hans Reitzels Forlag.

Ku, H. and A. Yuen-Tsang (2013). Capacity Building, in. Bevir, M, The Sage Handbook of Governance.

Labin, S. N., et al. (2012). "A research synthesis of the evaluation capacity building literature." American Journal of Evaluation 33(3): 307-338.

Lane, P. J. and M. Lubatkin (1998). "Relative absorptive capacity and interorganizational learning." Strategic Management Journal 19(5): 461-477.

Lawson, B. and D. Samson (2001). "Developing innovation capability in organisations: a dynamic capabilities approach." International journal of innovation management 5(03): 377-400.

Lennie, J. (2005). "An evaluation capacity-building process for sustainable community IT initiatives: Empowering and disempowering impacts." Evaluation 11(4): 390-414.

McCarthy, A. (2014). "Leading during uncertainty and economic turbulence: An investigation of leadership strengths and development needs in the senior Irish public sector." Advances in Developing Human Resources 16(1): 54-73.

McCauley-Smith, C., et al. (2013). "Individual leader to interdependent leadership: A case study in leadership development and tripartite evaluation." Advances in Developing Human Resources 15(1): 83-105.

Muir, D. (2014). "Mentoring and leader identity development: A case study." Human Resource Development Quarterly 25(3): 349-379.

Noya, A. and E. Clarence (2009). "Community capacity building: fostering economic and social resilience." Organisation for economic cooperation and development: 26-27.

O'Cass, A., et al. (2014). "Achieving new product success via the synchronization of exploration and exploitation across multiple levels and functional areas." Industrial Marketing Management 43(5): 862-872.

O'Connor, G. C., et al. (2018). Beyond the champion: institutionalizing innovation through people, Stanford University Press.

O'Reilly III, C. A. and M. L. Tushman (2013). "Organizational ambidexterity: Past, present, and future." Academy of management Perspectives 27(4): 324-338.

Palm, K. and J. Lilja (2017). "Key enabling factors for organizational ambidexterity in the public sector." International Journal of Quality and Service Sciences 9(1): 2-20.

Philippe, B. (2004). "Sociologie du changement dans les entreprises et les organisations." Le Seuil.

Raisch, S., et al. (2009). "Organizational ambidexterity: Balancing exploitation and exploration for sustained performance." Organization science 20(4): 685-695.

Simsek, Z. (2009). "Organizational ambidexterity: Towards a multilevel understanding." Journal of Management Studies 46(4): 597-624.

Simsek, Z., et al. (2009). "A typology for aligning organizational ambidexterity's conceptualizations, antecedents, and outcomes." Journal of Management Studies 46(5): 864-894.

Smith, W. K. and M. L. Tushman (2010). Managing strategic contradictions: A top management team model for simultaneously exploring and exploiting. Handbook of Top Management Teams, Springer: 60-70.

Spreitzer, G. M. (1995). "Psychological empowerment in the workplace: Dimensions, measurement, and validation." Academy of management Journal 38(5): 1442-1465.

Turner, J. R. and R. Baker (2018). "A review of leadership theories: identifying a lack of growth in the HRD leadership domain." European Journal of Training and Development 42(7/8): 470-498.

Uhl-Bien, M. and R. Marion (2009). "Complexity leadership in bureaucratic forms of organizing: A meso model." The Leadership Quarterly 20(4): 631-650.

Uotila, J., et al. (2009). "Exploration, exploitation, and financial performance: analysis of S\&P 500 corporations." Strategic Management Journal 30(2): 221-231.

Wang, C. L. and M. Rafiq (2014). "Ambidextrous organizational culture, Contextual ambidexterity and new product innovation: a comparative study of UK and C hinese high-tech Firms." British Journal of management 25(1): 58-76.

Warhurst, R. P. (2012). "Leadership development as identity formation: middle managers' leadership learning from MBA study." Human Resource Development International 15(4): 471-487.

Wei, Z., et al. (2014). "Organizational learning ambidexterity, strategic flexibility, and new product development." Journal of Product Innovation Management 31(4): 832-847.

Zhang, X., et al. (2012). "Understanding indigenous leadership research: Explication and Chinese examples." The Leadership Quarterly 23: 1063-1079. 